\title{
Respiratory Complications Before and After Liver Transplant
}

Journal of Intensive Care Medicine

$1-9$

(C) The Author(s) 2018

Reprints and permission:

sagepub.com/journalsPermissions.nav DOI: $10.1|77 / 08850666| 878 \mid 526$

journals.sagepub.com/home/jic

(S)AGE

\author{
Filipe S. Cardoso' and Constantine J. Karvellas ${ }^{2} \oplus$
}

\begin{abstract}
Respiratory complications before and after liver transplant are common, diverse, and potentially have a negative impact on patient outcomes. In this review, we discuss the most frequent respiratory conditions that patients may develop in the perioperative period. Their prevention and/or treatment may help to maximize the benefit these patients may derive from liver transplant. This review examines diagnostic and therapeutic approaches to these complications for hepatologists, surgeons, and critical care physicians.
\end{abstract}

\section{Keywords}

end-stage liver disease, respiratory failure, postoperative care, liver transplantation, hepatopulmonary syndrome, portopulmonary hypertension, hepatic hydrothorax

\section{Introduction}

Liver transplant (LT) is the definitive treatment for selected patients with either complicated cirrhosis or acute liver failure (ALF). Pulmonary complications before LT may have a negative impact on these patients' outcomes after surgery or even preclude such a procedure. Pulmonary complications early after LT may further impair morbidity and mortality. However, some of these respiratory complications may to some extent be prevented or treated. Besides improving clinical outcomes, such interventions may also optimize the use of healthrelated resources and costs. With this review, we discuss the most clinically relevant respiratory complications affecting patients in the peri-LT period. In doing so, we hope to contribute to the multidisciplinary care such patients require at this particular stage of their illness.

\section{Respiratory Complications Before Liver Transplant}

Patients with cirrhosis and portal hypertension may develop specific respiratory complications, including hepatic hydrothorax, hepatopulmonary syndrome, portopulmonary hypertension, and $\alpha$-1-antitrypsin deficiency emphysema (AATD). Albeit, not infrequent, hepatologists and intensivists need to have a high index of suspicion to pursuit such diagnoses. Furthermore, taking into account the impact of such respiratory conditions on these patients' prognosis, including access to LT, it is fundamental to detect and treat them as early as possible. In this section, we discuss not only these 4 noninfectious respiratory complications that may develop in patients with advanced cirrhosis but also a common infectious respiratory condition that may ensue in patients with either cirrhosis or ALFpneumonia.

\section{Hepatic Hydrothorax}

Definition and epidemiology. Hepatic Hydrothorax (HH) is defined by a pleural effusion that develops in patients with cirrhosis and/or portal hypertension in the absence of other underlying thoracic (eg, pneumonia, heart failure, and malignancy) or abdominal (eg, pancreatitis) etiologies. In a recent cohort, among 763 patients with cirrhosis and ascites, $13 \%$ had HH. ${ }^{1}$ In another cohort, among 862 patients with cirrhosis, $15 \%$ developed $\mathrm{HH}^{2}$

Pathophysiology. Hepatic Hydrothorax pathophysiology is not completely understood. It has been proposed that HH development resembles the mechanism of ascites accumulation in the context of portal hypertension. ${ }^{3}$ The combination of intra-

\footnotetext{
' Gastroenterology and Intensive Care Divisions, Hospital Curry Cabral, Central Lisbon Hospital Center, Nova Medical School, Nova University, Lisbon, Portugal

${ }^{2}$ Division of Gastroenterology (Liver Unit) and Department of Critical Care Medicine, University of Alberta, Edmonton, Canada

Received February 6, 2018. Received revised May 5, 2018. Accepted May 17, 2018.

\section{Corresponding Author:}

Constantine J. Karvellas, Division of Gastroenterology (Liver Unit), Department of Critical Care Medicine, School of Public Health Sciences, University of Alberta, I-40 Zeidler Ledcor Building, Edmonton, Alberta T6G-2X8, Edmonton, Canada.

Email: dean.karvellas@ualberta.ca
} 
abdominal positive pressure and intrathoracic negative pressure potentiates the movement of fluid from the peritoneal cavity into the pleural space through diaphragmatic fenestrations. ${ }^{4}$ These tissue defects, usually less than $1 \mathrm{~cm}$ in diameter, are more frequent on the right side, in proximity with the liver, as the left side of the diaphragm is more muscular and thicker. ${ }^{5,6}$ While HH is more frequently $(68 \%)$ right-sided, it can be left-sided (13\%) or bilateral $(19 \%){ }^{1}$

Clinical presentation and diagnosis. The clinical presentation of patients with $\mathrm{HH}$ varies widely, especially with the volume and rate of pleural fluid and ascites accumulation. Therefore, these patients may be asymptomatic, present dyspnea and abdominal discomfort due to large volume ascites, or evolve to respiratory failure.

The diagnosis of HH requires evidence of cirrhosis and portal hypertension (clinical, biochemical, radiology, and/or histopathology) and the exclusion of other causes of pleural effusion. Using a chest X-ray (frontal and lateral), most pleural effusions with $>250 \mathrm{~mL}$ are identifiable. ${ }^{7}$ Bedside chest ultrasound or computed tomography (CT) scan may be needed to diagnose smaller accumulations of fluid. ${ }^{8}$ Furthermore, CT scan is more accurate in excluding other pulmonary pathologies. A transthoracic echocardiogram (TTE) is often needed to exclude cardiac pathology.

If feasible, an ultrasound-guided thoracentesis should be performed for $\mathrm{HH}$ diagnosis. $\mathrm{HH}$ is usually a transudate (pleural/serum total protein ratio $<0.5 \mathrm{and} /$ or pleural/serum lactate dehydrogenase ratio $<0.6$ ) associated with portal hypertension (serum/pleural albumin $>1.1 \mathrm{~g} / \mathrm{dL}$ ). While uncomplicated $\mathrm{HH}$ has a polymorphonuclear cell count $\leq 250$ cells $/ \mu \mathrm{L}$, spontaneous bacterial empyema is defined by whether positive pleural fluid culture and cell count $>250$ cells $/ \mu \mathrm{L}$ or negative pleural fluid culture and a cell count $>500$ cells $/ \mu \mathrm{L} .{ }^{9}$

Other pleural fluid tests that should be requested include $\mathrm{pH}$, amylase, triglycerides, adenosine deaminase, and cytology. A complete septic screen is also mandatory, including sputum (tracheal aspirate in ventilated patients), blood, ascites, and urine. In a cohort of 120 patients with $\mathrm{HH}, 16$ patients had 24 events of spontaneous bacterial pleuritis; 10 of those episodes had no concomitant spontaneous bacterial peritonitis (SBP). ${ }^{9}$ The most frequent bacteria involved were Enterobacter species (eg, Escherichia coli and Klebsiella pneumonia), Streptococcus species, and Enterococcus species. ${ }^{9}$

Treatment and prognosis. The principles of $\mathrm{HH}$ treatment are based on those of ascites. ${ }^{10}$ Sodium restriction $(<2 \mathrm{~g} / \mathrm{d})$ and diuretics (spironolactone up to $400 \mathrm{mg} / \mathrm{d}$ and furosemide up to $160 \mathrm{mg} / \mathrm{d}$ ) are usually the first line of treatment. The goal would be to lose $0.5 \mathrm{~kg} / \mathrm{d}$ to $1 \mathrm{~kg} / \mathrm{d}$ while avoiding adverse effects, especially acute kidney injury and electrolyte disturbances (eg, hyponatremia and hypokalemia).

Spontaneous bacterial pleuritis is treated empirically much like SBP, usually with cefotaxime or ceftriaxone as first-line antibiotics. ${ }^{10}$ However, the microbiological profile of each hospital should be used for choosing the correct antibiotics.
Albumin cotherapy and long-term secondary prophylaxis with antibiotics are not as well established as in SBP.

For symptomatic patients, drainage via ultrasound-guided thoracentesis should be performed. While there is risk of pneumothorax or hemothorax, the procedure is usually safe. If there is concomitant large volume ascites, an ultrasound-guided paracentesis could be attempted prior to the thoracentesis, as this may help relieve patients' symptoms. Chest tube placement should be considered if there is pneumothorax, or pus or blood is identified after the thoracentesis. The drainage of large volumes of protein-rich pleural fluid with a chest tube in situ may increase the risk of acute kidney injury and electrolyte disturbances. ${ }^{11}$ Furthermore, it may be difficult to remove the chest tube due to rapid pleural fluid reaccumulation. ${ }^{12}$ Despite these concerns, the insertion of a pigtail catheter to drain the hydrothorax has been attempted and proved reasonably effective and safe. ${ }^{13}$

For patients warranting HH drainage every 2 to 3 weeks, despite sodium restriction and optimized diuretic therapy, other treatment options should be considered. ${ }^{3}$ Transjugular intrahepatic portosystemic shunt (TIPS) has been used for $\mathrm{HH}$ refractory to medical therapy. According to 1 meta-analysis, post-TIPS response rate was $73 \%$ and 45 -day mortality was $18 \% .{ }^{14}$ Contraindications to the procedure may be age $>70$ years, hepatic encephalopathy, large portal vein thrombosis, right-sided heart failure, elevated pulmonary arterial pressure, and a model for end-stage liver disease (MELD) score $>15$. $^{3,15}$

Video-assisted thoracoscopy with pleurodesis or surgical closure of the diaphragm fenestrations has been studied in small cohort studies. Despite reasonable response rates reported, the complication rate, especially infection, is still of concern. ${ }^{16,17}$ Therefore, these treatment options are to be considered mainly within an experimental context or as a last resort measure, namely, for palliation.

Liver transplantation (LT) is the definitive treatment for HH. Following diagnosis, patients with $\mathrm{HH}$ should be referred to a LT center. There is lack of evidence regarding any waitlist mortality excess due to HH; hence, there is no MELD exception points to apply. Outcomes post-LT have been reported as similar to other transplanted patients with an 8-year survival rate of $70 \% .^{18,19}$

\section{Hepatopulmonary Syndrome}

Definition and epidemiology. Hepatopulmonary syndrome (HPS) is defined by an oxygenation defect characterized by intrapulmonary vascular dilatation that develops in patients with cirrhosis and/or portal hypertension. Hepatopulmonary syndrome may occur in patients with coexistent cardiopulmonary conditions that further impair oxygenation. In a recent cohort, among 74 patients with cirrhosis, $23 \%$ had HPS. ${ }^{20}$ In another cohort, among 316 patients with cirrhosis, $26 \%$ developed HPS. ${ }^{21}$

Pathophysiology. Hepatopulmonary syndrome results from abnormal dilatation of pulmonary capillaries. ${ }^{22}$ Experimental studies suggest that these vascular alterations derive from at 
Table I. Diagnostic Criteria and Severity Classification of Hepatopulmonay Syndrome.

Hypoxemia cause and severity of disease
Alveolar arterial oxygen gradient $>$ I5 mm Hg (>20 mm Hg if age
$>64$ years)
Mild: $\mathrm{PaO}_{2} \geq 80 \mathrm{~mm} \mathrm{Hg}$
Moderate: $\mathrm{PaO}_{2} 60-79 \mathrm{~mm} \mathrm{Hg}$
Severe: $\mathrm{PaO}_{2} 50-59 \mathrm{~mm} \mathrm{Hg}$
$\quad$ Very severe: $\mathrm{PaO}_{2}<50 \mathrm{~mm} \mathrm{Hg}$
Pulmonary capillary dilatation confirmation
Contrast-enhanced transthoracic echocardiogram: injected air
bubbles appear delayed >3 cardiac cycles in the left cardiac
chambers or Radionuclide lung perfusion scan using technetium-
labeled macroaggregated albumin: injected particles are detected
in post-pulmonary capillaries (eg, brain, spleen, or kidneys)

Abbreviations: $\mathrm{FiO}_{2}$, oxygen inspired fraction; $\mathrm{PaCO}_{2}$, carbon dioxide arterial pressure; $\mathrm{PAO}_{2}$, alveolar oxygen pressure; $\mathrm{PaO}_{2}$, arterial oxygen pressure; Patm, atmospheric pressure; $\mathrm{PH}_{2} \mathrm{O}$, atmospheric water pressure.

${ }^{\mathrm{a}} \mathrm{PAO}_{2}-\mathrm{PaO}_{2}=\left[\mathrm{FiO}_{2}\left(\mathrm{Patm}-\mathrm{PH}_{2} \mathrm{O}\right)-\mathrm{PaCO}_{2} / 0.8\right]-\mathrm{PaO}_{2}$.

least 2 mechanisms: local increase in nitric oxide production due to endothelial stimulation by hepatic endothelin-1 or monocyte activation by bacterial endotoxins; and angiogenesis in which endothelial growth factor A and CX3CL1 factor seem to be involved. ${ }^{23,24}$ This pulmonary vasodilation results in ventilation-perfusion mismatch, which leads to hypoxemia. ${ }^{25}$

Clinical presentation and diagnosis. The clinical presentation of patients with HPS varies from being asymptomatic to present dyspnea or even progress to respiratory failure. While dyspnea upon standing (platypnea) and hypoxemia exacerbated in the upright position (orthodeoxia) are characteristic features, they are present in $<25 \%$ of patients. ${ }^{22}$

The diagnostic criteria of HPS are displayed in Table $1 .^{25,26}$ An arterial blood gas is necessary to calculate the alveolar arterial oxygen gradient. To confirm the pulmonary capillary dilatation, a contrast-enhanced TTE is the most sensitive test. $^{22}$ Alternatively, a radionuclide lung perfusion scan using technetium-labeled macroaggregated albumin (MAA) may be used. This test is especially useful if there is coexistent HPS and intrinsic lung disease with severe hypoxemia (arterial oxygen pressure $\left(\mathrm{PaO}_{2}\right)<60 \mathrm{~mm} \mathrm{Hg}$ ), as MAA brain uptake $\geq 6 \%$ suggests HPS is the most important contributor to hypoxemia. $^{27}$

Treatment and prognosis. There is no established medical therapy for HPS. Supplemental oxygen is used to avoid persistent hypoxemia. Controlling other causes that may additionally impair oxygenation (eg, hepatic hydrothorax, heart failure, and chronic obstructive pulmonary disease) is also necessary.

While the severity of liver disease has not been associated with the severity of hypoxemia, LT is the ultimate treatment for HPS. ${ }^{26}$ Following diagnosis, patients with HPS should be referred to a LT center. After LT, improvement in oxygenation is expected in almost all patients, and outcomes have been reported as similar to other transplanted patients with a 5-year survival rate of $76 \%{ }^{28,29}$ While lower pre-LT $\mathrm{PaO}_{2}$ has not been associated with increased waitlist mortality, it has been associated with worse post-LT outcomes. ${ }^{29}$ Although controversial, according to the Organ Procurement and Transplantation Network (OPTN) in the United States, patients with severe HPS in the waitlist for LT are offered at inclusion an exception MELD score of 22, and this is increased every 3 months if hypoxemia remains severe. ${ }^{26,29}$

\section{Portopulmonary Hypertension}

Definition and epidemiology. Portopulmonary hypertension (POPH) is defined by pulmonary arterial hypertension associated with portal hypertension with or without cirrhosis. ${ }^{22} \mathrm{Car}-$ diopulmonary etiologies of pulmonary arterial hypertension may coexist and need to be investigated. In a recent cohort, among $1235 \mathrm{LT}$ candidates, 5\% had POPH. ${ }^{30}$

Pathophysiology. Pathophysiology of POPH is not fully understood. Several factors have been associated with the arterial occlusion (due to vasoconstriction, endothelial and smooth muscle proliferation, in situ thrombosis, and plexogenic arteriopathy) that characterizes POPH: deficiency in endothelial prostacyclin synthase resulting in platelet dysfunction and increased level of endothelin 1; increased levels of estrogens in females; and portosystemic shunts. ${ }^{22,31}$ This pulmonary arterial hypertension results in ventilation-perfusion mismatch, which leads to hypoxemia. ${ }^{25}$

Clinical presentation and diagnosis. The clinical presentation of patients with $\mathrm{POPH}$ varies from being asymptomatic to present dyspnea or even to develop respiratory failure. Exertional dyspnea is the most common symptom reported. ${ }^{22,31}$ Features of right heart failure such as the following may be present in the most severe cases: peripheral edema on clinical examination; signs of right atrial enlargement, right ventricular hypertrophy, right axis deviation, or right bundle branch block on the 12-lead electrocardiogram, and increased right ventricular systolic pressure (RVSP) on TTE. ${ }^{22,25}$ Being a noninvasive test, RVSP evaluation has been proposed as the screening test for POPH with levels $\geq 40$ to $50 \mathrm{~mm} \mathrm{Hg}$ being used to select patients for right heart catheterization. ${ }^{22,31}$

Two hemodynamic patterns in patients with portal hypertension may be confounded with POPH, the hyperdynamic circulation of cirrhosis or fluid overload, both are with increased mean pulmonary artery pressure (mPAP) but normal pulmonary vascular resistance (PVR). Therefore, the diagnostic criteria of POPH depend on right heart catheterization that is displayed in Table $2 .^{22,31,32}$

Treatment and prognosis. Medical therapy for POPH has relied on 3 different classes of vasodilators, based on their use in primary pulmonary hypertension. Prostacyclin analogs, the most common being epoprostenol (intravenous administration), have been associated with improved mPAP and PVR. ${ }^{33,34}$ Endothelin receptor antagonists, the most frequently 
Table 2. Diagnostic Criteria and Severity Classification of Portopulmonay Hypertension.

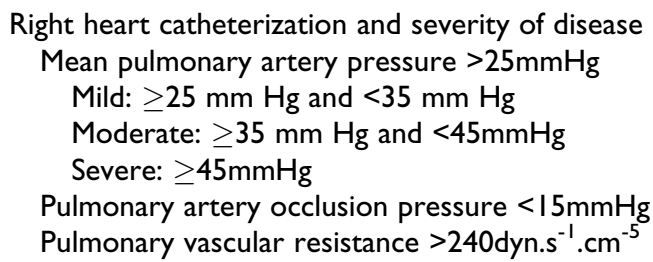

used being bosentan or ambrisentan (oral administration), have been associated with improved lung hemodynamics. ${ }^{35,36}$ This class of drugs may be associated with hepatotoxicity and thus warrant monitoring of liver blood tests. Finally, phosphodiesterase- 5 inhibitors, the most common being sildenafil, tadalafil, or vardenafil (oral administration), have also shown to benefit lung hemodynamics. ${ }^{37,38}$ Despite improving lung hemodynamics and early exercise capacity, these medications are yet to prove their impact in long-term survival.

Patients with POPH without treatment had a 5-year survival of $14 \% .{ }^{37}$ Survival post-LT worsens with pre-LT disease severity with perioperative mortality for patients with $\mathrm{mPAP}>50$ $\mathrm{mm}$ Hg reaching $100 \%{ }^{38}$ Therefore, according to the OPTN in the United States, patients with baseline moderate POPH who respond to vasodilator therapy (mPAP $<35 \mathrm{~mm} \mathrm{Hg}$ and PVR $<400$ dyn. $\mathrm{s}^{-1} \mathrm{~cm}^{-5}$ ) and have normal right ventricular function in the waitlist for LT are offered at inclusion an exception MELD score of 22, and this is increased every 3 months if these criteria are still true. ${ }^{22,25}$ Following LT, vasodilator therapy is often continued and 3-year survival has been reported as $77 \% .^{39,40}$

\section{$\alpha-I-A n t i t r y p s i n$ Deficiency Emphysema}

Definition and epidemiology. $\alpha$-1-antitrypsin deficiency emphysema is an autosomal-dominant disease characterized by reduced production of the serine protease inhibitor $\alpha-1$ antitrypsin (AAT). The most common deficient allele is the $\mathrm{Z}$ allele with a prevalence of $2 \%$ to $3 \%$ in the United States; the most frequent clinically relevant phenotype is the $\mathrm{ZZ}$ with a prevalence of $0.05 \%$ in the United States. ${ }^{41} \alpha$-1-Antitrypsin deficiency emphysema accounts for $1.1 \%$ of adult LTs and $3.5 \%$ of paediatric LTs in the United States. ${ }^{42}$

Pathophysiology. In the lungs, AAT functions normally by inactivating neutrophil elastase. In AATD, uninhibited neutrophil elastase activity causes destruction of alveolar elastin which leads to panacinar emphysema. ${ }^{43}$ In the liver, ZZ AATD is characterized by abnormal folding and polymerization of the ZZ protein. The accumulation of this protein in the hepatocytes causes cell death, fibrosis, and eventually cirrhosis. ${ }^{44}$

Clinical presentation and diagnosis. Recognizing patients with AATD is often difficult, as both lung and liver diseases have clinical and laboratory presentations similar to other etiologies.
Suspicion should prompt diagnostic testing if 1 or more of the following features are present: neonates, children, or adults with unexplained liver disease, adults with obstructive pulmonary syndrome incompletely reversible with optimized bronchodilators, adults with necrotizing panniculitis, or adults with c-ANCA positive vasculitis. ${ }^{45}$ In $\mathrm{Z}$ allele heterozygotes with active liver or vasculitic disease, the plasma AAT level may be normal; therefore, serum phenotyping by isoelectric focusing is the gold standard for diagnosing AATD. ${ }^{45}$

Treatment and prognosis. The medical therapy for AATD relies generally on oxygen support, bronchodilators, and eventually noninvasive ventilation (NIV). Specific augmentation therapy with $\alpha$-1-antiprotease (intravenous administration) may be beneficial in moderate lung disease (forced expiratory volume at 1 second $35 \%-60 \%$ ) but not in liver disease. ${ }^{46}$ Liver transplant and/or lung transplantation (LUT) are the ultimate treatments for AATD. Five-year post LT (ZZ homozygotes) and LUT survival rates have been reported as $80 \%$ and $38 \%$, respectively. ${ }^{44,47}$

\section{Pneumonia}

Definition and epidemiology. Pneumonia is an infection of the lungs. In patients with cirrhosis, it is usually the third most common cause of infection, following SBP and urinary tract infection (UTI).$^{48}$ In a recent cohort, among 946 patients with cirrhosis admitted to hospital, $46(4.9 \%)$ had pneumonia. ${ }^{49}$ In another cohort, among 377 patients with cirrhosis admitted to intensive care unit (ICU), 37 (9.8\%) were diagnosed with pneumonia. ${ }^{50}$ In patients with ALF, it is the most common infection. In an older cohort, among 50 patients with ALF admitted to ICU, $23(46.0 \%)$ had pneumonia. ${ }^{51}$

Pathophysiology. In patients with cirrhosis, the interplay of several nonclinical and clinical factors increases the risk of infection: quantitative and qualitative alterations in gut microbiota, increased permeability of the intestinal barrier, cirrhosisrelated immunodeficiency, genetic predisposition to infection, low protein content in ascites, variceal bleeding, and poor liver function. ${ }^{48}$ In patients with ALF, the inflammatory mediators released from the injured liver into the circulation may impair function of monocytes and increase the risk of infection. ${ }^{52}$

Clinical presentation and diagnosis. The clinical presentation of patients with pneumonia frequently includes dyspnea and fever. In one of the cohorts mentioned, among the 37 patients with cirrhosis and pneumonia admitted to ICU, $16(43.2 \%)$ required invasive mechanical ventilation (IMV) on admission. ${ }^{50}$ In another cohort mentioned, among the 23 patients with ALF and pneumonia admitted to ICU, 21 (91.3\%) required IMV during ICU stay. ${ }^{51}$

The final diagnosis of pneumonia encompasses clinical, biochemical, microbiological, and radiological features. A complete septic screen is mandatory, including sputum (tracheal aspirate or even broncoalveolar lavage in ventilated patients), 
blood, ascites, and urine. In the cohorts including patients with cirrhosis mentioned, the most common pathogens found were as follows: (1) for community-acquired pneumonia, Escherichia coli, Streptococcus pneumoniae, and Staphylococcus aureus and (2) for hospital-acquired or nosocomial pneumonia, $P$ aeruginosa, Enterobacter species, and $S$ aureus. ${ }^{49,50}$ In the cohort including patients with ALF mentioned, the most frequent bacteria isolated were $S$ aureus, $P$ aeruginosa, and Acinetobacter calcoaceticus. ${ }^{51}$ Multiresistant bacteria prevalence has been growing overtime most likely in association with the more frequent use of prophylactic antibiotics (eg, SBP) and need for invasive procedures and hospital contacts. ${ }^{48}$

Treatment and prognosis. The medical therapy for pneumonia relies initially on oxygen support and empirical or, if possible, adjusted antibiotics. The role of prophylactic antibiotics for pneumonia in cirrhosis or ALF has not been properly established. ${ }^{48,53}$ The microbiological profile of each hospital will be fundamental for choosing the correct antibiotics.

In 1 recent cohort, the 30-day post hospital admission mortality rate of patients with cirrhosis and pneumonia (32.0\%) was significantly worse than the ones who had other infections, incuding SBP (19.7\%), UTI (14.6\%), and other types $(13.8 \%) .{ }^{54}$ In another cohort, among patients with cirrhosis admitted to ICU with need for IMV, ICU mortality rate was $65.9 \% .{ }^{55}$ Furthermore, infection and longer ventilatordependency were significantly associated with worse mortality rates.

The prognosis of patients with cirrhosis or ALF and pneumonia definitively worsens if acute respiratory distress syndrome and/or septic shock ensues. ${ }^{52,55}$ In this context, organ support measures in the ICU are crucial. Although patients may need lung-protective ventilatory strategies (eg, low tidal volume and permissive hypercapnia, and high positive endexpiratory pressure), hemodynamic instability often requires resuscitation with fluids and vasopressors. Invasive monitoring of the hemodynamic status (eg, pulse contour cardiac output [PiCCO] studies) is warranted to avoid further impairment of the oxygenation capacity due to intrathoracic fluid accumulation. ${ }^{52,56}$ In the context of septic shock, initiation of antibiotics within 1 hour of diagnosis has been shown to reduce early mortality. ${ }^{55,57}$

Uncontrolled sepsis may lead to delisting patients from the LT waitlist. In 1 recent cohort, among 136 patients with cirrhosis admitted to hospital, 57 (41.9\%) were delisted or died within 6 months. ${ }^{58}$ Among this subgroup of patients, 23 (40.4\%) had respiratory failure during hospital stay, one of the most frequent organ failures. Furthermore, infection during the initial hospital stay meant a $42 \%$ increase in risk of delisting or death within 6 months. Therefore, preventive measures to decrease risk of nosocomial infection, frequent septic screen, and timely diagnosis and treatment of pneumonia in patients with cirrhosis or ALF seem to be of paramount importance.

\section{Early Respiratory Complications After Liver Transplant}

Patients who undergo LT frequently develop respiratory complications, including pulmonary edema, pleural effusion, atelectasis, pneumonia, and transfusion-related acute lung injury (TRALI). While some of these events may present entirely as postoperative complications, frequently there are pre (eg, liver, heart, kidney functions, smoking, and nutritional status) and/or intraoperative (eg, cold and warm ischemia times and transfusion of blood products) factors associated with their occurrence. ${ }^{59}$ Given their potentially negative impact on patient morbidity and mortality, timely identification and treatment are important.

\section{Pulmonary Edema, Pleural Effusion, and Atelectasis}

Definition and epidemiology. While pulmonary edema is the accumulation of fluid in the lung interstitium and alveoli, pleural effusion is the accumulation of fluid in the pleural cavity. Atelectasis occurs when there is loss of volume in a pulmonary anatomical region. In a recent cohort, among 90 patients who underwent LT, $16(17.8 \%)$ had pulmonary edema during ICU stay. ${ }^{60}$ In another cohort, among 187 patients who had LT, 70 (37.4\%) developed pleural effusion up to 48 hours following surgery. ${ }^{61}$ In a different cohort, among 204 patients who underwent LT, 131 (64.3\%) experienced atelectasis within 1 week post LT. ${ }^{62}$

Pathophysiology. Pulmonary edema may be driven by increased hydrostatic pressure (eg, fluid overload and heart failure) or wall permeability (eg, septic shock and liver failure) in pulmonary capillaries. ${ }^{63}$ Pleural effusion is often a transudate (eg, fluid overload, heart failure, residual portal hypertension) but may present as an exudate (eg, pneumonia). ${ }^{64}$ Atelectasis most frequently may be due to airway obstruction (eg, respiratory secretions impaction) or external compression of the lung (eg, pleural effusion and pneumothorax). ${ }^{62}$ Additionally, reduced chest movements due to postoperative pain or iatrogenic diaphragmatic dysfunction may lead to atelectasis. ${ }^{65}$

Clinical presentation and diagnosis. Patients with pulmonary edema, pleural effusion, or atelectasis may be asymptomatic or progressively develop dyspnea, with some of them evolving to respiratory failure. In one of the cohorts mentioned, among 187 patients who had LT, 64 (34.2\%) developed respiratory failure, with 36 of those (56.3\%) presenting more than 1 underlying respiratory complication (infectious or not). ${ }^{61}$ The consequences on oxygenation capacity largely depend on the severity and extent of each condition, with likely symptomatic examples being extensive alveolar edema, large bilateral pleural effusions, or complete lung collapse.

The diagnosis of these pulmonary complications is usually confirmed with a chest X-ray (frontal and lateral). ${ }^{7}$ If diagnostic doubts persist, a CT scan may be required. ${ }^{8}$ The differential diagnosis of pulmonary edema often requires a TTE to exclude 
Journal of Intensive Care Medicine $X X(X)$

cardiac pathology and that of pleural effusion depends on ultrasound-guided thoracentesis with pleural fluid analysis (see details in HH section). A complete septic screen is also mandatory, including sputum (tracheal aspirate in ventilated patients), blood, ascites (if still present), and urine.

Treatment and prognosis. The medical therapy of pulmonary edema and pleural effusion generally includes oxygen support and diuretics, but patients not responsive to these measures may require NIV. For atelectasis, the control of its underlying cause is of paramount importance; for example, to avoid respiratory secretions impaction, good bronchial toilette with judicious use of sedatives, regular aspirations, or bronchoscopy at times is helpful; to reverse a clinically significant pneumothorax (symptoms and thickness $>1 \mathrm{~cm}$ ), a pleural drain is warranted.

There is lack of studies evaluating the individual impact of pulmonary edema, pleural effusion, and atelectasis on the prognosis of patients who underwent LT. However, in one of the cohorts mentioned, pulmonary edema in this context was associated with longer ventilator-dependency and ICU stay. ${ }^{63}$

\section{Pneumonia}

Definition and epidemiology. The definition of pneumonia has been presented in the previous Pneumonia section. In a recent cohort, among 148 patients who underwent LT, 23 $(15.5 \%)$ developed hospital-acquired pneumonia in the ICU. ${ }^{66}$ In another cohort, among 228 patients who had LT, $19(8.3 \%)$ were diagnosed with hospital-acquired pneumonia in the ICU. ${ }^{67}$

Pathophysiology. Liver transplant recipients accumulate risk factors for pneumonia after transplant, for example, older age, cirrhosis, higher MELD score, lower platelet count, restrictive lung pattern, higher number of units of blood products transfused during surgery, longer ventilator dependency, iatrogenic atelectasis (see Pulmonary edema, pleural effusion, and atelectasis section), and immunosuppression. ${ }^{65,68}$

Clinical presentation and diagnosis. The clinical presentation and diagnosis of pneumonia have been described in the previous Pneumonia section. In one of the cohorts mentioned, among 23 patients with pneumonia, 22 (95.7\%) required IMV (14 were already ventilated at the time of diagnosis, whereas 8 were breathing spontaneously). ${ }^{66}$

In one of the cohorts mentioned, the most common pathogens found were as follows: Hemophilus influenzae, P aeruginosa, and $S$ aureus. ${ }^{66}$ In another cohort mentioned, the most common bacteria isolated were as follows: $P$ aeruginosa, $S$ aureus, and other Enterobacter species. ${ }^{68}$

Treatment and prognosis. Treatment of pneumonia has been discussed in the previous Pneumonia section. In one of the cohorts mentioned, among 23 patients with pneumonia, 4 (17.4\%) died while in the ICU. ${ }^{66}$ In another cohort mentioned, pneumonia was associated with longer ICU stay and higher hospital mortality. ${ }^{68}$ Furthermore, pneumonia has also been identified as the major cause for ICU readmission within the hospital stay following LT. ${ }^{65}$

\section{Transfusion-Related Acute Lung Injury}

Definition and epidemiology. Transfusion-related acute lung injury (ALI) is defined as the acute lung injury that develops up to 6 hours following transfusion of 1 or more units of blood or blood products. ${ }^{69}$ In a recent cohort, among 632 patients who underwent LT, 9 (1.4\%) had hypoxemia compatible with TRALI during surgery. ${ }^{70}$

Pathophysiology. The pathophysiology of TRALI has been described by the 2 hit theory: (1) The first insult consists of priming and adherence of neutrophils to the pulmonary endothelium; and (2) the second insult includes activation of these primed neutrophils, resulting in the release of reactive oxygen species that cause capillary leak and pulmonary edema. ${ }^{71}$ Risk factors for TRALI include the following: alcoholism, smoking, liver surgery, shock, positive fluid balance, higher peak airway pressure on the ventilator, higher interleukin 8 level, transfusion of blood or blood products from female donors, and higher volumes of HLA class II antibody or antihuman neutrophil antigen. ${ }^{72}$

Clinical presentation and diagnosis. Transfusion-related ALI should be suspected and excluded in all cases of dyspnea and hypoxemia (especially with respiratory failure, that is, $\mathrm{PaO}_{2} /$ inspired oxygen fraction $\left(\mathrm{FiO}_{2}\right)$ ratio $<300 \mathrm{~mm} \mathrm{Hg}$ ) developing up to 6 hours following transfusion of any amount of blood or blood products.

Aspiration of undiluted fluid from the tracheal tube may help to establish the nature of the ongoing pulmonary edema: increased capillary hydrostatic pressure if the tracheal fluidplasma protein ratio is $<0.65$ or wall permeability (as in TRALI) if $>0.75 .^{71}$ PiCCO studies may also assist with such differentiation. The confirmation of TRALI diagnosis requires investigating the donor and recipient for passively transfused antibodies. $^{71,72}$

Treatment and prognosis. The treatment of TRALI is fundamentally supportive. Lung-protective ventilatory strategies (see Pneumonia section) are recommended as in ALI from other causes. If patients develop hemodynamic instability, vasopressors should be started and invasive hemodynamic monitoring (eg, PiCCO studies) is often helpful to help manage fluid balance. An ETT to exclude cardiac pathology and a full septic screen (see Pneumonia section) to exclude sepsis are warranted in this context.

TRALI is usually a self-limited condition, and thus its prognosis is often better than ALI from other etiologies. ${ }^{71}$ In a recent cohort including general critically ill patients, among 89 patients with TRALI, 37 were breathing spontaneously before diagnosis and from those 29 (78.4\%) required IMV; 
also, 53 were independent of vasopressors before diagnosis and from those 13 (24.5\%) ended up on vasopressors. ${ }^{73}$ In comparison to controls, patients with TRALI had longer ventilator dependency and ICU stay. Of the 89 patients with TRALI, $15(16.9 \%)$ died during hospital stay. In another cohort mentioned, among 9 patients with TRALI after LT, one (11.1\%) died postoperatively.

Transfusion-related ALI is not easy to prevent, but some strategies may be worthwhile to consider; for example, understand patient-specific clinical risk factors for TRALI, optimize patients pre-LT in terms of hemoglobin, platelet count, and clotting factors, titrate transfusions of blood and blood products to necessary targets during peri-LT period, and discuss the preferential use of blood from male donors. ${ }^{71}$

\section{Conclusions}

Respiratory complications before and after LT are common and potentially can have a significant impact on posttransplant outcomes. Therefore, clinicians should be aware of their specificities, display a high index of suspicion, and institute therapy in a timely fashion so transplant recipients can succeed post-LT.

\section{Declaration of Conflicting Interests}

The author(s) declared no potential conflicts of interest with respect to the research, authorship, and/or publication of this article.

\section{Funding}

The author(s) received no financial support for the research, authorship, and/or publication of this article.

\section{ORCID iD}

Constantine J. Karvellas (D) http://orcid.org/0000-0002-1555-1089

\section{References}

1. Matei D, Pasca S, David A, et al. Hepatic hydrothorax in patients with cirrhosis and ascites - its prevalence and association with other cirrhosis complications. J Hepatol. 2017;66(1):S135.

2. Chen TA, Lo GH, Lai KH. Risk factors for spontaneous bacterial empyema in cirrhotic patients with hydrothorax. J Chin Med Assoc. 2003;66(10):579-586.

3. Krok KL, Cárdenas A. Hepatic hydrothorax. Semin Respir Crit Care Med. 2012;33(1):3-10.

4. Hewett LJ, Bradshaw ML, Gordon LL, Rockey DC. Diagnosis of isolated hepatic hydrothorax using peritoneal scintigraphy. Hepatology. 2016;64(4):1364-1366.

5. Zenda T, Miyamoto S, Murata S, Mabuchi H. Detection of diaphragmatic defect as the cause of severe hepatic hydrothorax with magnetic resonance imaging. Am J Gastroenterol. 1998;93(11): 2288-2289.

6. Huang PM, Chang YL, Yang CY, Lee YC. The morphology of diaphragmatic defects in hepatic hydrothorax: thoracoscopic finding. J Thorac Cardiovasc Surg 2005;130(1):141-145.

7. Mammarappallil JG, Anderson SA, Danelson KA, Stitzel JA, Chiles C. Estimation of pleural fluid volumes on chest radiography using computed tomography volumetric analysis: an update of the visual prediction rule. J Thorac Imaging. 2015;30(5): 336-339.

8. Svigals PZ, Chopra A, Ravenel JG, Nietert PJ, Huggins JT. The accuracy of pleural ultrasonography in diagnosing complicated parapneumonic pleural effusions. Thorax. 2017;72(1):94-95.

9. Xiol X, Castellví JM, Guardiola J, et al. Spontaneous bacterial empyema in cirrhotic patients: a prospective study. Hepatology. 1996;23(4):719-723.

10. Moore KP, Wong F, Gines P, et al. The management of ascites in cirrhosis: report on the consensus conference of the international ascites club. Hepatology. 2003;38(1):258-266.

11. Orman ES, Lok AS. Outcomes of patients with chest tube insertion for hepatic hydrothorax. Hepatol Int. 2009;3(4):582-586.

12. Liu LU, Haddadin HA, Bodian CA, et al. Outcome analysis of cirrhotic patients undergoing chest tube placement. Chest. 2004; 126(1):142-148.

13. Sharaf-Eldin M, Bediwy AS, Kobtan A, et al. Pigtail catheter: a less invasive option for pleural drainage in egyptian patients with recurrent hepatic hydrothorax. Gastroenterol Res Pract. 2016; 2016:4013052.

14. Ditah IC, Al Bawardy BF, Saberi B, Ditah C, Kamath PS. Transjugular intrahepatic portosystemic stent shunt for medically refractory hepatic hydrothorax: a systematic review and cumulative meta-analysis. World J Hepatol. 2015;7(13):1797-1806.

15. Dhanasekaran R, West JK, Gonzales PC, et al. Transjugular intrahepatic portosystemic shunt for symptomatic refractory hepatic hydrothorax in patients with cirrhosis. Am J Gastroenterol. 2010; 105(3):635-641.

16. Hou F, Qi X, Guo X. Effectiveness and safety of pleurodesis for hepatic hydrothorax: a systematic review and meta-analysis. Dig Dis Sci. 2016;61(11):3321-3334.

17. Jung Y. Surgical treatment of hepatic hydrothorax: a "Four-Step Approach." Ann Thorac Surg. 2016;101(3):1195-1197.

18. Xiol X, Tremosa G, Castellote J, et al. Liver transplantation in patients with hepatic hydrothorax. Transpl Int. 2005;18(6): 672-675.

19. Sersté T, Moreno C, Francoz C, et al. The impact of preoperative hepatic hydrothorax on the outcome of adult liver transplantation. Eur J Gastroenterol Hepatol. 2010;22(2):207-212.

20. Voiosu AM, Daha IC, Voiosu TA, et al. Prevalence and impact on survival of hepatopulmonary syndrome and cirrhotic cardiomyopathy in a cohort of cirrhotic patients. Liver Int. 2015;35(12): 2547-2555.

21. Pascasio JM, Grilo I, López-Pardo FJ, et al. Prevalence and severity of hepatopulmonary syndrome and its influence on survival in cirrhotic patients evaluated for liver transplantation. Am J Transplant. 2014;14(6):1391-1399.

22. Machicao VI, Balakrishnan M, Fallon MB. Pulmonary complications in chronic liver disease. Hepatology. 2014;59(4):1627-1637.

23. Fallon MB, Abrams GA, Luo B, Hou Z, Dai J, Ku DD. The role of endothelial nitric oxide synthase in the pathogenesis of a rat model of hepatopulmonary syndrome. Gastroenterology. 1997; 113:606-614

24. Zhang J, Luo B, Tang L, et al. Pulmonary angiogenesis in a rat model of hepatopulmonary syndrome. Gastroenterology. 2009; 136:1070-1080. 
25. Krowka MJ, Fallon MB, Kawut SM, et al. International liver transplant society practice guidelines: diagnosis and management of hepatopulmonary syndrome and portopulmonary hypertension. Transplantation. 2016;100(7):1440-1452.

26. Krowka MJ, Wiesner RH, Heimbach JK. Pulmonary contraindications, indications, and MELD exceptions for liver transplantation: a contemporary view and look forward. J Hepatol. 2013; 59(2):367-374.

27. Krowka MJ, Wiseman GA, Burnett OL, et al. Hepatopulmonary syndrome: a prospective study of relationships between severity of liver disease, $\mathrm{PaO}(2)$ response to $100 \%$ oxygen, and brain uptake after (99 m)Tc MAA lung scanning. Chest. 2000;118(3): 615-624.

28. Gupta S, Castel H, Rao RV, et al. Improved survival after liver transplantation in patients with hepatopulmonary syndrome. Am J Transplant. 2010;10(2):354-363.

29. Goldberg DS, Krok K, Batra S, Trotter JF, Kawut SM, Fallon MB. Impact of the hepatopulmonary syndrome MELD exception policy on outcomes of patients after liver transplantation: an analysis of the UNOS database. Gastroenterology. 2014;146(5): 1256-1265.

30. Krowka MJ, Swanson KL, Frantz RP, et al. Portopulmonary hypertension: results from a 10-year screening algorithm. Hepatology. 2006;44(6):1502-1510.

31. Rodríquez-Roisin R, Krowka MJ, Hervé P, Fallon MB; ERS (European Respiratory Society) Task Force-PHD Scientific Committee. Highlights of the ERS Task Force on pulmonary-hepatic vascular disorders (PHD). J Hepatol. 2005;42(6):924-927.

32. Rodríguez-Roisin R, Krowka MJ, Hervé P, Fallon MB; ERS Task Force Pulmonary-Hepatic Vascular Disorders (PHD) Scientific Committee. Pulmonary-hepatic vascular disorders (PHD). Eur Respi. J. 2004;24(5):861-880.

33. Krowka MJ, Frantz RP, McGoon MD, Severson C, Plevak DJ, Wiesner RH. Improvement in pulmonary hemodynamics during intravenous epoprostenol (prostacyclin): A study of 15 patients with moderate to severe portopulmonary hypertension. Hepatology. 1999;30(3):641-648.

34. Fix OK, Bass NM, De Marco T, Merriman RB. Long-term followup of portopulmonary hypertension: effect of treatment with epoprostenol. Liver Transpl. 2007;13(6):875-885.

35. Hoeper MM, Seyfarth HJ, Hoeffken G, et al. Experience with inhaled iloprost and bosentan in portopulmonary hypertension. Eur Respir J. 2007;30:1096-1102.

36. Cartin-Ceba R, Swanson K, Iyer V, Wiesner RH, Krowka MJ. Safety and efficacy of ambrisentan for the treatment of portopulmonary hypertension. Chest. 2011;139(1):109-114.

37. Swanson KL, Wiesner RH, Nyberg SL, Rosen CB, Krowka MJ. Survival in portopulmonary hypertension: Mayo clinic experience categorized by treatment subgroups. Am J Transplant. 2008; 8(11):2445-2453.

38. Krowka MJ, Plevak DJ, Findlay JY, Rosen CB, Wiesner RH, Krom RA. Pulmonary hemodynamics and perioperative cardiopulmonary related mortality in patients with portopulmonary hypertension undergoing liver transplantation. Liver Transpl. 2000;6(4):443-450.
39. Savale L, Sattler C, Coilly A, Conti F, Renard S, Francoz C, Bouvaist H, Feray C, Borentain P, Jaïs X, Montani D, et al. Long-term outcome in liver transplantation candidates with portopulmonary hypertension. Hepatology. 2017;65(5):1683-1692.

40. DeMartino ES, Cartin-Ceba R, Findlay JY, Heimbach JK, Krowka MJ. Frequency and outcomes of patients with increased mean pulmonary artery pressure at the time of liver transplantation. Transplantation. 2017;101(1):101-106.

41. de Serres FJ, Blanco I, Fernandez-Bustillo E. PI S and PI Z alpha-1 antitrypsin deficiency worldwide. A review of existing genetic epidemiological data. Monaldi Arch Chest Dis. 2007;67: 184-208.

42. Kemmer N, Kaiser T, Zacharias V, Neff GW. Alpha-1-antitrypsin deficiency: outcomes after liver transplantation. Transplant Proc. 2008;40(5):1492-1494.

43. Stoller JK, Aboussouan LS. Alpha1-antitrypsin deficiency. Lancet. 2005;365(9478):2225-2236

44. Carey EJ, Iyer VN, Nelson DR, Nguyen JH, Krowka MJ. Outcomes for recipients of liver transplantation for alpha-1antitrypsin deficiency-related cirrhosis. Liver Transpl. 2013; 19(12):1370-1376.

45. American Thoracic Society; European Respiratory Society. American Thoracic Society/European Respiratory Society statement: standards for the diagnosis and management of individuals with alpha-1 antitrypsin deficiency. Am J Respir Crit Care Med. 2003;168(7):818-900.

46. Luisetti M, Ferrarotti I, Corda L, et al. Italian registry of patients with alpha-1 antitrypsin deficiency: general data and quality of life evaluation. COPD. 2015;12 Suppl 1:52-57.

47. Banga A, Gildea T, Rajeswaran J, Rokadia H, Blackstone EH, Stoller JK. The natural history of lung function after lung transplantation for $\alpha(1)$-antitrypsin deficiency. Am J Respir Crit Care Med. 2014;190(3):274-281.

48. Jalan R, Fernandez J, Wiest R, et al. Bacterial infections in cirrhosis: a position statement based on the EASL Special Conference 2013. J Hepatol. 2014;60(6):1310-1324.

49. Fernández J, Acevedo J, Castro $M$, et al. Prevalence and risk factors of infections by multiresistant bacteria in cirrhosis: a prospective study. Hepatology. 2012;55(5):1551-1561.

50. Levesque E, Hoti E, Azoulay D, et al. Prospective evaluation of the prognostic scores for cirrhotic patients admitted to an intensive care unit. J Hepatol. 2012;56(1):95-102.

51. Rolando N, Harvey F, Brahm J, et al. Prospective study of bacterial infection in acute liver failure: an analysis of fifty patients. Hepatology. 1990;11(1):49-53.

52. Cardoso FS, Marcelino P, Bagulho L, Karvellas CJ. Acute liver failure: An up-to-date approach. J Crit Care. 2017;39:25-30.

53. Karvellas CJ, Cavazos J, Battenhouse H, et al; US Acute Liver Failure Study Group. Effects of antimicrobial prophylaxis and blood stream infections in patients with acute liver failure: a retrospective cohort study. Clin Gastroenterol Hepatol. 2014;12(11): 1942-1949.

54. Hung TH, Tseng CW, Hsieh YH, Tseng KC, Tsai CC, Tsai CC. High mortality of pneumonia in cirrhotic patients with ascites. BMC Gastroenterol. 2013;13:25. 
55. Levesque E, Saliba F, Ichaï P, Samuel D. Outcome of patients with cirrhosis requiring mechanical ventilation in ICU. $J$ Hepatol. 2014;60(3):570-578.

56. Olson JC, Karvellas CJ. Critical care management of the patient with cirrhosis awaiting liver transplant in the intensive care unit. Liver Transpl. 2017;23(11):1465-1476.

57. Kok B, Karvellas CJ, Abraldes JG, et al; Cooperative antimicrobial therapy of septic shock (CATSS) research group. The impact of obesity in cirrhotic patients with septic shock: a retrospective cohort study. Liver Int. 2017; doi: 10.1111/liv.13648. (Epub ahead of print).

58. Reddy KR, O'Leary JG, Kamath PS, et al; North American Consortium for the Study of End-Stage Liver Disease. High risk of delisting or death in liver transplant candidates following infections: results from the North American Consortium for the study of end-stage liver disease. Liver Transpl. 2015;21(7):881-888.

59. Pedersen MR, Choi M, Brink JA, Seetharam AB. Pretransplant factors and associations with postoperative respiratory failure, ICU length of stay, and short-term survival after liver transplantation in a high MELD population. $J$ Transplant. 2016;2016:6787854.

60. Singh N, Gayowski T, Wagener MM, Marino IR. Pulmonary infiltrates in liver transplant recipients in the intensive care unit. Transplantation. 1999;67(8):1138-1144.

61. Durán FG, Piqueras B, Romero M, et al. Pulmonary complications following orthotopic liver transplant. Transpl Int. 1998; 11(suppl 1):S255-S259.

62. Ulubay G, Kirnap M, Er Dedekarginoglu B, Kupeli E, Oner Eyuboglu F, Haberal M. Awareness of respiratory failure can predict early postoperative pulmonary complications in liver transplant recipients. Exp Clin Transplant. 2015;13(suppl 3):110-114.

63. Snowden CP, Hughes T, Rose J, Roberts DR. Pulmonary edema in patients after liver transplantation. Liver Transpl. 2000;6(4): 466-470.
64. Adetiloye VA, John PR. Intervention for pleural effusions and ascites following liver transplantation. Pediatr Radiol. 1998; 28(7):539-543.

65. Cardoso FS, Karvellas CJ, Kneteman NM, Meeberg G, Fidalgo P, Bagshaw SM. Respiratory rate at intensive care unit discharge after liver transplant is an independent risk factor for intensive care unit readmission within the same hospital stay: a nested casecontrol study. J Crit Care. 2014;29(5):791-796.

66. Weiss E, Dahmani S, Bert F, et al. Early-onset pneumonia after liver transplantation: microbiological findings and therapeutic consequences. Liver Transpl. 2010;16(10):1178-1185.

67. Saner FH, Olde Damink SW, Pavlakovic G, et al. Pulmonary and blood stream infections in adult living donor and cadaveric liver transplant patients. Transplantation. 2008;85(11): 1564-1568.

68. Levesque E, Hoti E, Azoulay D, et al. Pulmonary complications after elective liver transplantation-incidence, risk factors, and outcome. Transplantation. 2012;94(5):532-538.

69. Kleinman S, Caulfield T, Chan P, et al. Toward an understanding of transfusion-related acute lung injury: statement of a consensus panel. Transfusion. 2004;44(12):1774-1789.

70. Morita Y, Pretto EA Jr. Increased incidence of transfusion-related acute lung injury during orthotopic liver transplantation: a short report. Transplant Proc. 2014;46(10):3593-3597.

71. Looney MR, Gropper MA, Matthay MA. Transfusion-related acute lung injury: a review. Chest. 2004;126(1):249-258.

72. Toy $\mathrm{P}$, Gajic $\mathrm{O}$, Bacchetti $\mathrm{P}$, et al. Transfusion-related acute lung injury: incidence and risk factors. Blood. 2012;119(7): 1757-1767.

73. Looney MR, Roubinian N, Gajic O, et al; Transfusion-Related Acute Lung Injury Study Group. Prospective study on the clinical course and outcomes in transfusion-related acute lung injury. Crit Care Med. 2014; 42(7):1676-1687. 